\title{
Future Digital Design and Manufacturing: Embracing Industry 4.0 and Beyond
}

\author{
Sheng-Feng Qin ${ }^{1} \cdot$ Kai Cheng ${ }^{2}$
}

Published online: 1 August 2017

(C) The Author(s) 2017. This article is an open access publication

\begin{abstract}
This research highlight overviews the development roadmap of digital design and manufacturing and focuses on the future development directions under the Industries 4.0.
\end{abstract}

Keywords Digital design - Future manufacturing · Industry 4.0

Digital design and manufacturing have been around for several decades from the numerical control of machine tools and automating engineering design in 1960s, through early Computer Aided Design (CAD)/Computer Aided Engineering analysis (CAE)/Computer Aided Manufacturing (CAM), to modern digital design and manufacturing [1], and cloud manufacturing [2] converging into product lifecycle management (PLM) [3,4] and Internet-enabled personalized manufacturing [5].

Digital design and manufacturing technologies provide a great support for product realization from design conception and engineering to manufacturing, sales and services of a product. In the past, their developments and evolutions are driven greatly by other technological advances, such as those in materials, electronics, software, and ICT (information and computing) Technologies.

Sheng-Feng Qin

sheng-feng.qin@northumbria.ac.uk

Kai Cheng

Kai.cheng@bruinel.ac.uk

1 School of Design, Northumbria University, Newcastle upon Tyne NE1 8ST, UK

2 College of Engineering, Design and Physical Sciences, Brunel University London, Uxbridge UB8 3PH, UK
Now when we look at the horizon of the Industry 4.0 manufacturing scenarios and the emerging/evolving technologies, what are the challenges facing to our digital design and manufacturing research community and the industry? Examples of these technologies are novel manufacturing technology, such as additive manufacturing, ICTs, such as Cyber-Physics Systems (CPS), Big Data, the Internet of Things (IoTs), Artificial intelligence (AI), Digital Twin, and SMAC (Social, Mobile, Analytics, Cloud) and product and design technology, such as Smart Products, User Experience (UX) and Human Centered Design (HCD). In order to provide some insights into those questions, we organized an international workshop for scientists, engineers, scholars and research students to exchange ideas and update technical knowledge on related topics and published a special issue at this journal.

What are the driving forces [6] for Industry 4.0 or similar future manufacturing strategies such as "Made in China 2025"? On the one hand, we are facing some big social, economic and environmental challenges including ever-increasing global competitive pressure, personalized products/service, shrinking product lifecycles and fast changing technologies. These require horizontal integration of manufacturing value chains, such as [7] on integration of through-life product intelligence within smart products and smart manufacturing systems. On the other hand, with the increasing usage of information and communication technologies for the autonomy within the manufacturing environment or creating smart factory with Cyber-Physicals systems [8], there are requirements for vertical integration of manufacturing systems with CPS.

From a system point of view, future digital design and manufacturing research consists of four major research perspectives related to the manufacturing process, devices, software and engineering. The key technological enablers 
for implementing Industry 4.0 manufacturing environment are three interdependent ICT technologies: Internet of Thing, Cyber-Physical Systems and Smart Factory. Internet of Thing helps to create Cyber-Physical systems and the Cyber-Physical system helps to realize Smart Factories including Smart Products. Therefore, Smart Factory is regarded as a major vision of Industry 4.0 [7].

The selected 29 papers in the special issue provide some reference to the current research trends and challenges on digital design and manufacturing. Their research themes are closely related to the four research perspectives.

Under the manufacturing process perspective, two main research themes are (1) vertical integration with Internet of Thing, and Cyber-Physical Systems, and (2) horizontal integration with worldwide value chains. Vertical integration with Cyber-Physical Systems can support the concept of the smart factory, enabling (partly) autonomous and selforganized processes, which lead to increased efficiency and flexibility. The applications of Cyber-Physical Systems can also be extent to the self-aware health management of manufacturing systems and maintenance scheduling. Furthermore, the interaction study on the interplay of the machining process, the machine tools and the CPS systems needs more attentions.

Under the theme of horizontal integration with worldwide value chains, horizontal integration with supply chain can lead to better quality assurance systems by seamless integration of in-process production data and information internally and managing suppliers more effectively and efficiently. In addition, there is a need to the integration of customers, users and people in the early stage of product innovation to realize the human centered design and innovation from "design for people", to "design by people" and "design with people". It is also important to have the through lifecycle integration between smart product and smart manufacturing, which leads to entire smart manufacturing system.

In the view of devices perspective, the researches cover two themes: (1) physical devices and (2) device interfacing.

For physical device development, nanoparticles, nanomaterials and sensor technologies are being explored in the application. For device interfacing, wireless device connection problems, human-machine and human-system interfacing and interaction are taken into account. Examples are a smart and effective interfacing assistive system for the elder drivers by combining and interfacing various sensor devices, a smart power system solution for a household in the UK by connecting and interfacing several renewables properly and a smart cutting tool integrated with smart machining process. Some recent research focuses on platform technologies for integrating social sensors to support social manufacturing.
Under the software perspective, most of research attentions have been paid to (1)production control and regulation and (2) Product design and development processing control. Some researches investigate integrated manufacturing process quality analysis and control approaches based on Bayesian network and big data analysis. Others explore rapid online object identification and production control, such as a measured surface localization method for contour error evaluation, quality inspection and error compensation, and an energy-resource efficiency management method with in-process virtual management. In product design and collaborative processing control, researches focus on system simulation-driven multidisciplinary collaborative product design and development, such as spatiotemporal synchronization process control methods for collaborative simulation carried out on distributed computing devices.

Under the engineering perspective, the selected papers cover two themes: (1) product design and development, and (2) production and manufacturing engineering.

For product design and development, the role of digitalization in emotional product design has been highlighted and an demonstrative example is transferring 3D digital models into relief product models. Meanwhile, performance-driven design methods for complex engineering product development are well investigated by studying design product data models, design parameters' impact on product performance, and complex relationships among the design parameters. Others focused on conceptual design methods of complex mechatronic products by investigating customers' requirement modelling, design change propagation modelling, bio-mimicry design and concurrent multi-product development.

For production engineering, main researches are focused on design optimization, additive manufacturing and the optimization of production line for improving production efficiency.

Overall, future digital design and manufacturing will embrace the challenges and opportunities in the Industry 4.0 era in line with the SMAC phenomenon (Social Networking, Mobility, Analytics based on Big data and Cloud computing) which is increasingly playing a powerful role for future innovative design and manufacturing.

Open Access This article is distributed under the terms of the Creative Commons Attribution 4.0 International License (http://crea tivecommons.org/licenses/by/4.0/), which permits unrestricted use, distribution, and reproduction in any medium, provided you give appropriate credit to the original author(s) and the source, provide a link to the Creative Commons license, and indicate if changes were made. 


\section{References}

1. Kuang-Hua Chang. e-Design: Computer Aided Engineering Design. Elsevier Inc, 2015, ISBN: 978-0-12-382038-9.

2. Wei-Dong Li, Mehnen JöRN. Cloud manufacturing- distributed computing technologies for global and sustainable manufacturing. Springer, 2013, ISBN: 978-1-4471-4934-7 (Print),978-1-44714935-4 (Online).

3. JohnStar. Product lifecycle management. Volume 1- 21st Century Paradigm for Product Realization. 3rd ed. Springer, 2015, ISBN 978-3-319-17440-2 electronic book.

4. JohnStark. Product lifecycle management. Volume 12-The Devil is in the Details. 3rd ed. Springer, 2016, ISBN 978-3-319-24436-5 electronic bk.

5. Kai Cheng, Richard Bateman J. e-Manufacturing: characteristics, applications and potentials. Progress in Natural Science, 2008, 18: $1323-1328$.

6. Robert Harrison, Daniel Vera, Bilal Ahmad. Engineering the smart factory. Chinese Journal of Mechanical Engineering, 2016, 29(6): 1046-1051.

7. Alexander Duffy, Ian Whitfield, William Ion, et al. Smart products through-Life: research roadmap. The University of Strathclyde Publishing, 2016, ISBN 978-1-909522-17-6.

8. Federal Ministry of Education and Research of Germany. (2013). Recommendations for implementing the strategic initiative INDUSTRIE 4.0-Final report of the Industries 4.0 Working Group, http://www.acatech.de/fileadmin/user_upload/Baumstruk tur_nach_Website/Acatech/root/de/Material_fuer_Sonderseiten/ Industrie_4.0/Final_report_Industrie_4.0_accessible.pdf, accessed on July 5, 2017.
Sheng-Feng Qin is a Full Professor of Digital Design, Northumbria University Newcastle, UK. He received his PhD degree in Design Technology from University of Wales, UK in 2000. Before joining Northumbria School of Design, he was a Lecturer and then Senior Lecturer in Product Design at Brunel University between 2002 and 2013. Before that, he was a post-doctoral Research Fellow at Loughborough University between 2000 and 2001, and a Research Assistant at Cardiff Metropolitan University between 1998 and 1999. From 1996 to 1997, he was an Academic Visiting Scholar at Birmingham University and an Assistant/Associate Professor at East China Jiaotong University of China between 1988 and 1996. His research interest include digital design and manufacturing. He has authored/coauthored over 160 papers.

Kai Cheng is a chair Professor in Manufacturing Systems and currently the Theme Leader for Ultraprecision and Micro/Nano Manufacturing Theme at Brunel University London. His research interests include ultraprecision machining, design of high precision machines, smart tooling and smart machining, and sustainable manufacturing systems. Professor Cheng and his team have enjoyed working closely with industrial companies in the UK, Europe, USA and Far East. Professor Cheng is a Charted Engineer and a Fellow of the IMechE and IET, the European Editor for International Journal of Advanced Manufacturing Technology and a member of the Editorial Board at other 4 international journals. Professor Cheng was also honored with the Qianren Professorship in 2010 at Harbin Institute of Technology, China. 